\title{
Digital vertebral morphometry performed by DXA: a valuable opportunity for identifying fractures during bone mass assessment
}

Patrícia Muszkat', Marília Brasilio Rodrigues Camargo',

Barbara Santarosa Emo Peters², Ilda Sizue Kunii', Marise Lazaretti-Castro'

1 Division of Endocrinology, School of Medicine, Federal University of São Paulo (Unifesp), São Paulo, SP, Brazil ${ }^{2}$ Department of Nutrition, Faculty of Public Health, University of São Paulo (USP), São Paulo, SP, Brazil

Correspondence to: Patricia Muszkat

Rua Brás Cardoso, 219 04510-030 - São Paulo, SP, Brazil patymuszkat@hotmail.com

Received on Apr/29/2014

Accepted on Jan/13/2015

DOI: 10.1590/2359-3997000000020

\begin{abstract}
Objectives: To evaluate the usefulness of vertebral morphometry in identifying unreferred vertebral fractures and correlate potential risk factors. Subjects and methods: Female patients above 45 years, postmenopausal for at least 2 years, diagnosed with osteoporosis and undergoing treatment for at least three months were considered eligible. All of them underwent bone densitometry and vertebral morphometry performed by concomitant DXA. The presence of fractures was defined between T7 and L4; only moderate and severe fractures were considered for analysis. All volunteers were submitted to laboratory tests, anthropometry and responded a questionnaire on their lifestyle habits and medical history. Results: Thirty two (17\%) out of the 188 female patients presented with at least one vertebral fracture, among whom only $4(12.5 \%)$ were previously aware of the fracture. The fractures were mainly located on the thoracic spine. Nine patients had severe fractures $(28.1 \%)$, whereas 23 had moderate fractures $(71.9 \%)$. On average, patients with fractures were 5 years older and weighed 5 kilograms less than those without fractures. The creatinine clearance was on average $9 \mathrm{~mL} / \mathrm{min}$ less in patients with vertebral fracture. The assessment of vertebral fractures by morphometry is a fast, accurate and complementary method associated with low radiation exposure for identifying moderate and severe vertebral fractures. Predisposition to vertebral fractures does not depend solely on BMD. Arch Endocrinol Metab. 2015;59(2):98-104
\end{abstract}

\section{Keywords}

Postmenopausal women; Genant; vertebral fracture; vertebral fracture assessment

\section{INTRODUCTION}

$\mathrm{B}$ one fractures are the main cause of morbidity and mortality associated with osteoporosis. Fractures of long bones, such as that of the proximal femur, are usually fall-related, causing severe pain and incapacity, which lead patients to seek for immediate medical care. Vertebral fractures, however, may occur without obvious trauma and be associated with nonspecific symptoms (1). Most spinal fractures are not clinically recognized at the time they occur: two out of three radiographically detected vertebral fractures are asymptomatic findings (1). A large proportion of symptomatic fractures are associated with mild pain that tends to disappear in two to three weeks. Even vertebral fractures associated with moderate to severe pain can remain undiagnosed, since there are several other conditions that cause back pain.
Vertebral fractures cause loss of stature; chronic pain; abuse and harmful use of anti-inflammatory and analgesic drugs; increased risk of falls; reduced lung capacity; sleep disorders; increased patient dependency on others; decreased appetite (2); which all markedly impair patients' medical condition and quality of life. Most vertebral fractures occur at an earlier age than hip fractures (3), which is an important early indicator of disease severity. The mortality rate 5 years after a vertebral fracture is $20 \%$ higher than expected for the same age (4). Additionally, vertebral fractures, even if asymptomatic, are predictors of increased risk of new fractures (5-11), therefore their identification is important for designing the clinical treatment.

Clinical studies have shown that the existing treatments for osteoporosis increase spinal BMD between $4-12 \%$ and decrease the rate of vertebral fractures by $40-70 \%(12-13)$. An early radiologic diagnosis, fol- 
lowed by the appropriate treatment, aids in preventing new fractures (14). Therefore it is important to identify vertebral fractures as early as possible.

The vertebral fracture assessment (VFA) performed by digital morphometry during a dual-energy X-ray absorptiometry (DXA) bone densitometry scan is a great opportunity for detecting vertebral fractures, which, by and large, might remain clinically unrecognized, but that could have relevant clinical implications.

The aim of the current study is to assess the prevalence of moderate and severe vertebral fractures identified by vertebral morphometry performed during DXA bone densitometry scans and its relation to the possible risk factors for osteoporosis in a population of postmenopausal patients being treated for osteoporosis at the outpatient clinic of metabolic bone diseases at the Department of Endocrinology, Federal University of São Paulo.

\section{PATIENTS AND METHODS}

Two hundred and five women diagnosed with osteoporosis and registered in the database of patients being followed up at the outpatient clinic of metabolic bone diseases, at the school-hospital from Escola Paulista de Medicina (Unifesp), took part in this study. The patients were invited to participate in the study either by telephone or in-person contact during their appointments in 2009. Data collection took place between June and December 2009. Eligible patients were aged 45 years or older, postmenopausal for at least two years, diagnosed with osteoporosis at some point, and receiving treatment for at least three months. The criteria used for diagnosing osteoporosis were those proposed by the World Health Organization (WHO): the patients with a T-score less than or equal to -2.5 in their lumbar spine, femoral neck and/or total femur bone densitometry scans were classified as osteoporotic. The official guidelines of the Brazilian Society for Clinical Densitometry, as published on the official website of this entity, were followed.

The current study received approval from the Research Ethics Committee at Unifesp (ERB n. 0839/08). All of the participating patients signed a voluntary informed consent form.

All of the patients underwent bone densitometry scans in a Discovery A equipment $\left(\right.$ Hologic $^{\circledR}$, Bedford, MA, USA, software version 12.3) for assessing bone mass; body fat mass; lean body mass; and vertebral frac- tures (digital morphometry - Figure 1). The analyzed sites were lumbar spine, femur and whole body. Vertebral fracture assessment was performed in the same unit, immediately after the densitometry scans, with the patient in supine position and rotation of the unit arm for image acquisition. The assessment of vertebrae was conducted by placing 6 points on each vertebral body (on the anterior, medial and posterior portions of both the upper and lower parts of each vertebra). The software was used for calculating the anterior, medial and posterior heights of each vertebra, which allowed for the determination of the vertebra's deformity type and degree according to the Genant method (Figure 2). Such method classifies a fracture according to its severity, each vertebra being assigned a score: 0 , if there is no fracture; 1,2 or 3 , if the fracture is mild, moderate or severe, respectively. In mild fractures, the reduction in height of the anterior, medial and posterior portions is $20-25 \%$; in moderate fracture; it is $25-40 \%$; and in severe fractures, higher than $40 \%$. Moderate to severe vertebral fractures between T7 and L4 vertebrae were considered for analysis. All of the 188 VFA images

A
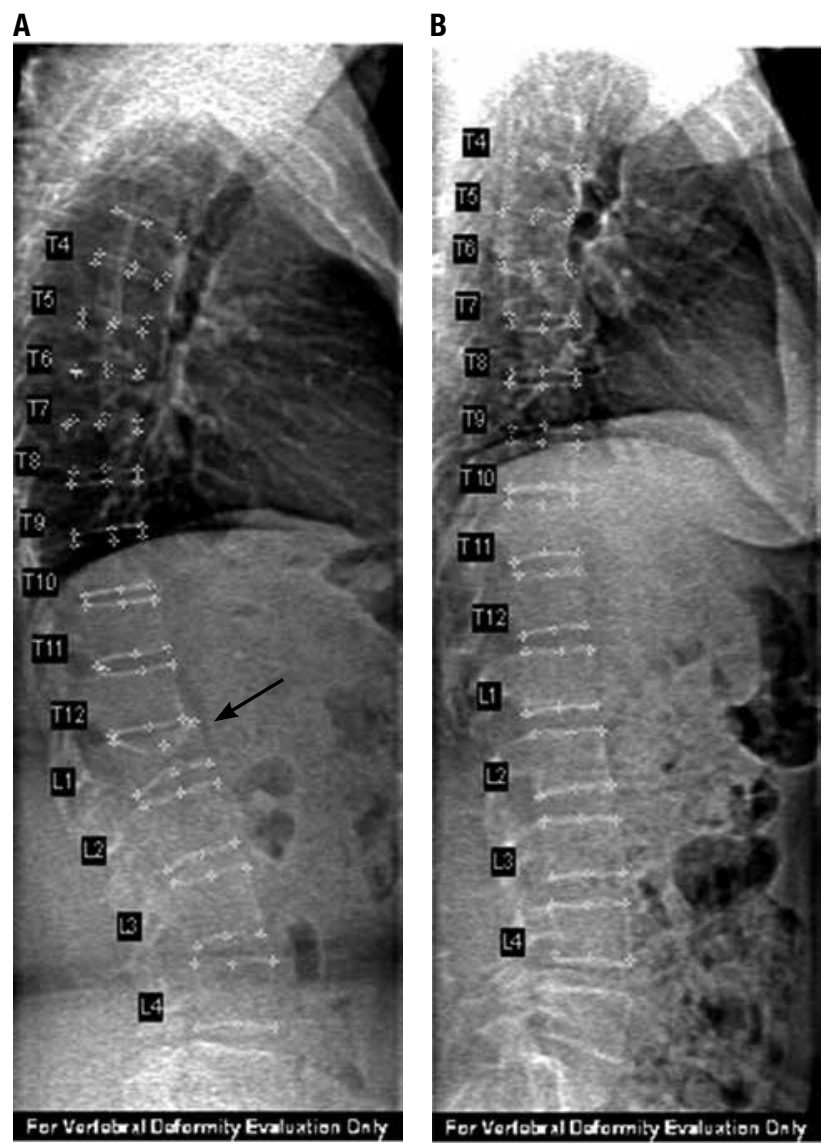

Figure 1. Example analysis of morphometric assessments comparing a severe biconcave fracture at L1 (A) and normal morphometry (B). 
were also evaluated by the semi quantitative method, in which the vertebrae deformity is graded only by visual inspection. Furthermore, 20 VFA images (10 of each group) were randomly assigned for two blinded physicians for a semiquantitative analysis to evaluate the presence or absence of a moderate or severe fracture between T7 and L4.

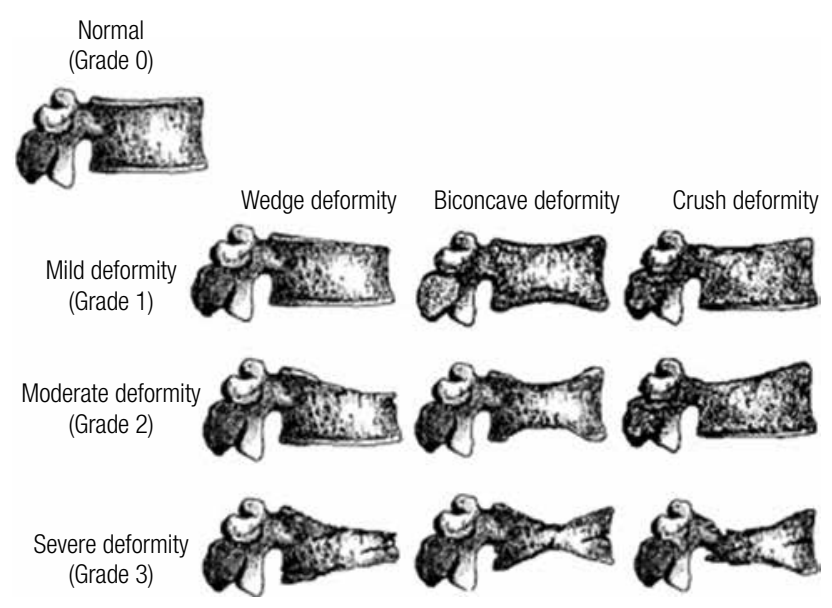

Figure 2. Schematic diagram of the semi-quantitative grading system for vertebral fractures: reproduced from Genant and cols. (15).

\section{Analytical methods}

\section{Laboratory parameters}

All patients had blood samples collected for measuring PTH; carboxy-terminal telopeptide of type 1 collagen (CTX); 25-hydroxyvitamin D (25OHD); creatinine; alkaline phosphatase activity $(\mathrm{AP})$; total calcium $(\mathrm{Ca})$; phosphorus $(\mathrm{P})$; amino-terminal propeptide of type $\mathrm{I}$ collagen (PINP). Additionally, urine was also collected for measuring calcium (UCa) and creatinine (UCr) in the isolated samples. $\mathrm{Ca}, \mathrm{P}$ and $\mathrm{UCa}$ were measured by an automatized colorimetric method. Both UCr and serum creatinine were measured by a kinetic colorimetric method. Clearance of creatinine (CrClear) was estimated by applying the Cockcroft-Gault equation (16). The $\mathrm{UCa} / \mathrm{UCr}$ ratio was calculated. AP was measured by an enzymatic method (Olympus AU640 analyzer, USA). CTX, PINP and PTH were measured using commercially available kits (chemiluminescence, Roche, Elecsys 2010 analyzer, USA). For CTX, the intra- and interassay coefficients of variation (CV) were 4.6 and $4.7 \%$, respectively; for PINP, the CVs were 1.8 and $2.7 \%$, respectively; and for PTH, the CVs were 3.0 and 3.5\%, respectively. $25 \mathrm{OHD}$ was measured by chemiluminescence (DiaSorin, Liaison analyzer, USA), with intra- and inter-assay CVs at 1.62 and 5.61\%, respectively.

\section{Anthropometric data}

Body mass and height were measured using a digital scale and a wall stadiometer. Body mass index (BMI) was calculated as the ratio between body mass $(\mathrm{kg})$ and the square of height $\left(\mathrm{m}^{2}\right)$.

\section{Questionnaire}

The patients responded questions on their age; lifestyle habits (smoking habits and alcohol consumption); comorbidities (diabetes mellitus, specifically); fracture history dating to any time in their life or specifically after age 45; and current medications. Patients were classified as smokers or non-smokers; those who denied current smoking habits were considered as non-smokers.

\section{Statistical analysis}

The Statistical Package for the Social Science (SPSS) version 19.0 (SPSS Inc., Chicago, Illinois, EUA) was used for conducting the statistical analysis. All variables were subjected to the Kolmogorov-Smirnov test to assess the normality of data distribution. Independent Student's t-test was used for comparing the anthropometric, laboratory and densitometric data obtained for the two groups (with and without fractures). The associations among categorical variables were evaluated by using the chi-squared test and $\mathrm{p}<0.05$ was considered significant. Agreement between observers was calculated using percentage of agreement and the $\kappa$ statistic: $\kappa=\left(p_{0}-p_{c}\right) /\left(1-p_{c}\right)$, where $p_{0}=$ the proportion of units in which the judges agreed; and $\mathrm{p}_{\mathrm{c}}=$ the proportion of units for which agreement is expected by chance (17).

\section{RESULTS}

Among the 205 patients selected for taking part in the study, 3 were deceased and 14 were not interested. Thus, data were obtained from a total of 188 patients, of which $32(17 \%)$ presented with at least one moderate or severe vertebral fracture, and among whom only $4(12.5 \%)$ the fracture had been previously diagnosed. Most patients $(87.5 \%)$ were not aware of the presence of fractures and no description of vertebral fractures was found in their medical records, so, such information was unknown even by their doctors. Six (18,7\%) out of these 32 patients had more than one vertebral fracture, with one patient presenting with 4 fractures. Among the 4 patients who were previously aware of the existing fracture, 3 presented with more than one vertebral fracture. 
The fractures were mainly located on the thoracic spine, with $56 \%$ of the cases occurring at the Tll and T1 2 vertebrae ( 9 involving each one of these), as can be seen in figure 3 . As for fracture severity, we found 9 patients with severe fractures $(28.1 \%)$ and 23 with moderate fractures $(71.9 \%)$. The semiquantitative analysis showed the same results.

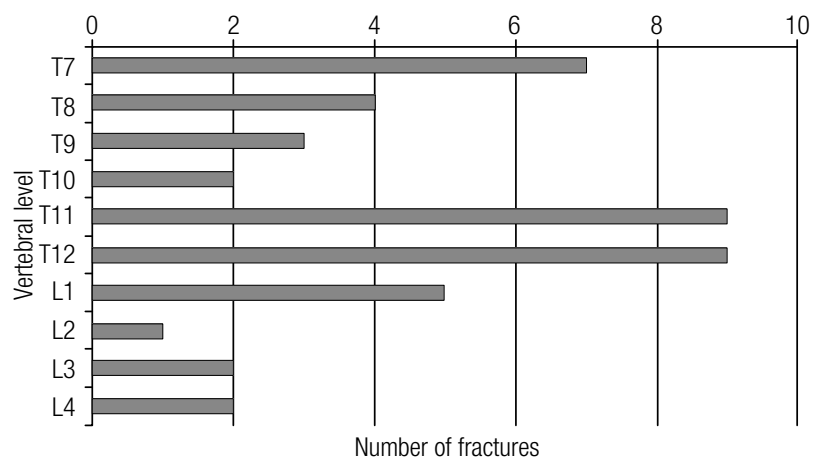

Figure 3. Distribution of vertebral fractures.

There was an agreement of $95 \%$ with the first blinded physician reading of the exams regarding the presence or absence of moderate or severe vertebral fracture and of $100 \%$ with the second one. The $\kappa$ statistic showed a $\kappa=0,9$ for the first blinded physician and a $\kappa$ $=1,0$ for the second one.

The results obtained from the anthropometric measurements, laboratory tests and densitometry scans from patients with and without vertebral fractures (VF) assessed by VFA are shown in tables 1 and 2 . The only statistically significant data between groups were age; clearance of creatinine; body fat mass; and total body mass. There were no other statistically significant differences for any parameters evaluated.

Considering the 188 participants, patients age varied between 48 and 86 years (mean age of 68 ). In the group of patients with vertebral fractures (VF), the mean age was 5 years more than that in the group of patients without VF. On average, patients with VF weighted $5 \mathrm{~kg}$ less than those without fractures. CrClear was on average $9 \mathrm{~mL} / \mathrm{min}$ less in patients with vertebral fracture. In the group of patients with VF, $16(50 \%)$ patients had CrClear less than $60 \mathrm{~mL} / \mathrm{min}$, whereas in the group of patients without fractures that figure amounted to 52 (33.3\%). Total body composition scans of patients with fractures showed on average 2,633 $\mathrm{g}$ fat and 3,992 $\mathrm{g}$ total mass less when compared to patients without fracture.
Table 1. Comparison of anthropometric and laboratory characteristics between the two groups: patients with and without vertebral fractures, as detected by digital morphometry performed by DXA

\begin{tabular}{lccc}
\hline & $\begin{array}{c}\text { Patients } \\
\text { without } \\
\text { fractures } \\
\mathbf{( 1 5 6 )} \\
\text { Mean } \pm \text { SD }\end{array}$ & $\begin{array}{c}\text { Patients } \\
\text { with } \\
\text { fractures } \\
\mathbf{( 3 2 )}\end{array}$ & Pean \pm SD \\
\hline (t-test) \\
\hline Age (years) & $67 \pm 9$ & $72 \pm 8$ & $0.010^{*}$ \\
Body mass (kg) & $60.2 \pm 10.8$ & $55.9 \pm 7.6$ & $0.032^{*}$ \\
Height (cm) & $152.9 \pm 6.3$ & $151.1 \pm 4.8$ & 0.113 \\
BMI (kg/m²) & $25.7 \pm 4.1$ & $24.4 \pm 2.9$ & 0.107 \\
Age of menopause onset (years) & $45.3 \pm 6.5$ & $47.4 \pm 6.7$ & 0.113 \\
P1NP (ng/mL) & $28.2 \pm 22$ & $22.6 \pm 13$ & 0.172 \\
CTX (ng/mL) & $0.19 \pm 0.18$ & $0.18 \pm 0.15$ & 0.648 \\
PTH (pg/mL) & $56 \pm 23$ & $57 \pm 28$ & 0.833 \\
250HD (ng/mL) & $24.3 \pm 13.8$ & $26.1 \pm 10.6$ & 0.494 \\
Creatinine (mg/dL) & $0.78 \pm 0.21$ & $0.78 \pm 0.18$ & 0.989 \\
CrClear (mL/min) & $68.5 \pm 20.9$ & $59.8 \pm 16.0$ & $0.028^{*}$ \\
Ca (mg/dL) & $9.3 \pm 0.4$ & $9.3 \pm 0.5$ & 0.811 \\
P (mg/dL) & $3.5 \pm 0.4$ & $3.5 \pm 0.5$ & 0.922 \\
AP (U/L) & $67.6 \pm 34.0$ & $59.3 \pm 14.4$ & 0.175 \\
UCa/UCr & $0.09 \pm 0.06$ & $0.10 \pm 0.09$ & 0.268 \\
\hline
\end{tabular}

${ }^{*}$ Statistically significant data.

Table 2. Comparison of body composition and bone mineral density results between the two groups: patients with and without vertebral fractures, as detected by digital morphometry performed by DXA

\begin{tabular}{|c|c|c|c|}
\hline & $\begin{array}{c}\text { Patients without } \\
\text { fractures (156) } \\
\text { Mean } \pm \text { SD }\end{array}$ & $\begin{array}{c}\text { Patients with } \\
\text { fractures (32) } \\
\text { Mean } \pm \text { SD }\end{array}$ & $P$ (t-test) \\
\hline $\begin{array}{l}\text { Lumbar spine } \\
\text { BMD }\end{array}$ & $0.737 \pm 0.111$ & $0.720 \pm 0.132$ & 0.441 \\
\hline $\begin{array}{l}\text { Lumbar spine } \\
\text { T-score }\end{array}$ & $-2.8 \pm 1.0$ & $-2.9 \pm 1.2$ & 0.440 \\
\hline $\begin{array}{l}\text { Femoral neck } \\
\text { BMD }\end{array}$ & $0.648 \pm 0.100$ & $0.623 \pm 0.086$ & 0.200 \\
\hline $\begin{array}{l}\text { Femoral neck } \\
\text { T-score }\end{array}$ & $-1.8 \pm 0.8$ & $-2.0 \pm 0.7$ & 0.216 \\
\hline Total femur BMD & $0.744 \pm 0.108$ & $0.714 \pm 0.110$ & 0.147 \\
\hline $\begin{array}{l}\text { Total femur } \\
\text { T-score }\end{array}$ & $-1.6 \pm 0.89$ & $-1.8 \pm 0.9$ & 0.173 \\
\hline $\begin{array}{l}\text { Total body BMD } \\
\text { (g) }\end{array}$ & $0.914 \pm 0.083$ & $0.887 \pm 0.076$ & 0.092 \\
\hline Total body T-score & $-2.1 \pm 0.9$ & $-2.4 \pm 0.8$ & 0.092 \\
\hline Body fat mass (g) & $21627.9 \pm 6945.5$ & $18994.3 \pm 5275.4$ & $0.044^{*}$ \\
\hline $\begin{array}{l}\text { Lean body mass } \\
\text { (g) }\end{array}$ & $37208.7 \pm 4544.5$ & $35945.9 \pm 3670.9$ & 0.142 \\
\hline $\begin{array}{l}\text { Lean body mass } \\
+ \text { BMC }\end{array}$ & $38741.4 \pm 4656.4$ & $37383.4 \pm 3767.7$ & 0.124 \\
\hline Total body mass & $60369.4 \pm 10661.3$ & $56377.7 \pm 6952.4$ & $0.044^{*}$ \\
\hline$\%$ fat & $35.0 \pm 6.1$ & $33.2 \pm 6.3$ & 0.140 \\
\hline
\end{tabular}


According to their questionnaires, no patient reported relevant alcohol consumption; $11.7 \%$ were current or past smokers, $42.5 \%$ of them presented with at least one fracture after age 45 , diabetes was reported by $19 \%$, but the distribution of these factors were not different between the groups with and without VF. Previous or current use of glucocorticoids were reported by $11(5,8 \%)$, but none of them in the fractured group.

Considering patients' current treatment, besides calcium and cholecalciferol supplementation (according to the diet), most of them $(\mathrm{n}=142,75.5 \%)$ were using bisphosphonates at the time the assessment was performed; $16(8.5 \%)$ were receiving raloxifene; 2 (1.06\%) were being treated with teriparatide; 28 (14.8\%) were receiving only calcium and/or cholecalciferol supplementation, with no significant difference between the groups.

\section{DISCUSSION}

The aim of this study was to assess the applicability of digital morphometry performed by VFA in detecting previously undiagnosed vertebral fractures in a population comprised of osteoporosis patients receiving treatment on an outpatient basis. The results showed that morphometry was able to detect moderate or severe vertebral fractures in $17 \%$ of such patients, in $87.5 \%$ of whom the fracture was unknown. In other words, approximately 1 out 7 patients receiving regular specialized treatment on an outpatient basis presented with an unknown vertebral fracture. In a study by Jager and cols., in which VFA was performed prospectively on all patients referred for DXA for bone mass assessment, the prevalence of moderate or severe vertebral fractures in patients with osteoporosis was $22 \%$ (18), very similar to the results observed by us.

Vertebral fracture assessment conducted by quantitative morphometry performed by X-ray absorptiometry (DXA) allows us to detect prevalent vertebral fractures, which are often not clinically recognized at the time they occur. Many studies had already validated the reliability of VFA interpretation against radiographs, mainly in detecting moderate to severe vertebral fractures (19-21). As shown by others, using VFA, clinicians correctly identified $94 \%$ of radiographically defined grade 2 and grade 3 vertebral fractures and 96\% of non-fractures vertebrae were correctly identified as normal on VFA (19).

The fact that VFA can be performed at the same time BMD is measured constitutes a valuable oppor- tunity. The relative risk of new fractures is increased 4.4 times in the presence of a vertebral fracture. Additionally, it also increases the risk of fragility fractures at other sites as well (5). A vertebral fracture is associated with a $19 \%$ chance of new vertebral fractures within the next 12 months (22).

An additional advantage is the simultaneous visualization of both thoracic and lumbar spine on a single image, thus using low exposure. The radiation dose for VFA is 3 micro-Sieverts $(\mu \mathrm{Sv})$, whereas that for a simple radiograph of the lumbar spine is $600 \mu S_{v}(23)$. A $3 \mu S v$ radiation dose is considered extremely low and comparable to the exposure dose received during a normal day (23). Since it is a digital technique, VFA allows for image manipulation and, thus, visualization enhancement, which leads to more accurate measurements. Besides, the parallel distortion caused by the X-rays' obliquity in relation to the vertebra is minimized, for the VFA performed by DXA emits rays that are perpendicular to the vertebra, especially when conducted at the supine position. VFA acquisition increases scan time in 10-15 seconds in addition to the time required for placing the patient in lateral decubitus position. The quantitative analysis is laborious, as measurements are performed individually on each vertebra. Nevertheless, it is possible to proceed in a so-called semi-quantitative manner, in which the vertebrae are graded solely by visual inspection without performing direct measurements on each vertebra, which facilitates the work and, consequently, reduces the cost of test. Several studies have already shown an excellent correlation between quantitative and semi-quantitative analyses (15,24-26) specially when referring to moderate and severe fractures.

One disadvantage of VFA is that the visualization of vertebrae above T7 is hindered by the juxtaposition of thoracic structures. On the other hand, osteoporotic vertebral fractures are uncommon in this region. As shown by others, severe and moderate fractures above T7 are less than $5 \%$ of prevalent vertebral fractures (18). There are difficulties for assessing the vertebrae in this region even with the use of radiography, which is considered as the standard imaging method for assessing fractures (18).

The detection of mild fractures, however, presents difficulties both for VFA as by conventional radiographs (27). Such fact reflects the inherent difficulty that exists in determining minimal deformities in the vertebrae (grade 1 fractures), regardless of the method. 
Furthermore, mild fractures (grade l) have been shown to have lesser clinical importance given their weaker association with new fractures, causing lesser loss of stature and less back pain (28). The severity of vertebral fractures has proven better at predicting a non-vertebral fracture than has BMD itself (8). For this reason, only moderate and severe fractures between $\mathrm{T} 7$ and L4 were included in our analysis.

The exact cost of this diagnostic method has not been well established in several countries yet. In 2006, the amount paid by Medicare in Los Angeles for a VFA was $\$ 40.48$ (US Dollars) versus $\$ 84.94$ (US Dollars) for a radiograph of the thoracic and lumbar spine (29).

This investigation corroborates previous studies that showed that predisposition to fracture is not dependent solely on BMD. In our population, there was no difference in BMD between the groups. Considering that all patients were receiving treatment, some of them showed densitometry scan results compatible with osteopenia at the test conducted for this study. Other risk factors played an important role in predicting the risk of vertebral fracture, such as age, total body mass and body fat mass.

Adipocytes and osteoblasts are derived from the same progenitor cells in the mesenchymal tissue, therefore there can potentially exist autocrine and paracrine effects of adiponectin on bone metabolism. Adiponectin is a hormone that is exclusively secreted by adipose tissue into the blood stream. Its blood plasma levels are inversely related to the percentage of body fat in adults. Some studies have already shown there exists a relation between serum adiponectin and risk of fractures in men, irrespectively of other factors like BMI and BMD. This relation, however, has not been established in women $(30)$.

The difference in renal function was probably due to older age and lower weight observed in the group with $\mathrm{FV}$, since there was no difference in the serum creatinine levels in both groups. Nonetheless, that may have contributed to greater fragility, as renal dysfunction progresses with abnormalities of bone turnover and mineralization, leading to a loss of bone strength (31).

Most patients were receiving treatment with bisphosphonates and cholecalciferol and, therefore, the correlation with bone remodeling markers, PTH and 25OHD was hindered.

In summary, vertebral fractures were diagnosed by VFA realized during DXA examination in $17 \%$ of patients followed in an outpatient clinic for osteoporosis, and in more than $80 \%$ of them this diagnosis was hitherto unknown. Despite the fact that all patients in this study already had a diagnosis of osteoporosis, knowing whether or not a vertebral fracture exists is of utmost importance, since such knowledge can change their therapeutic approaches. Various studies have already shown that treatment reduces not only the risk of new fractures but also the number of hospitalizations (3235 ). Therefore, routine VFAs in addition to densitometry scans might modify the evaluation of the risk of new fractures of such a patient, changing the diagnosis from osteopenia or osteoporosis to "severe osteoporosis" in cases where a VF is detected. To take the opportunity of the presence of the patient in the diagnostic center and to use the full resources that modern DXA devices offer, increasing the accuracy of assessing the risk of fractures, seems a quite appropriate strategy.

Acknowledgments: Roche Diagnósticos do Brasil kindly provided PTH, CTX and PINP assay kits.

Funding: this research was sponsored by the Fundação de Amparo à Pesquisa do Estado de São Paulo (Fapesp); Grant 08/55567-7. Patricia Muszkat received a scholarship from the Conselho Nacional de Desenvolvimento Científico e Tecnológico (CNPq).

Disclosure: no potential conflict of interest relevant to this article was reported.

\section{REFERENCES}

1. Cooper C, Atkinson EJ, MichaelO'Fallon W, Melton III JL. Incidence of clinically diagnosed vertebral fractures: a populationbased study in Rochester, Minnesota, 1985-1989. J Bone Min Res. 1992;7:221-7.

2. Silverman SL. The clinical consequences of vertebral compression fracture. Bone. 1992;13(suppl. 2):S27-31.

3. Riggs BL, Melton III LJ. The worldwide problem of osteoporosis: Insights afforded by epidemiology. Bone. 1995;17(5):505s-11s.

4. Cooper C, Atkinson EJ, Jacobsen SJ, O'Fallon WM, Melton III LJ. Population-based study of survival after osteoporotic fractures. Am J Epidemiol. 1993;137:1001-5.

5. Klotzbuecher CM, Ross PD, Landsman PB, Abbott III TA, Berger $M$. Patients with prior fractures have an increased risk of future fractures: a summary of the literature and statistical synthesis. J Bone Miner Res. 2000;15:721-39.

6. Black DM, Arden NK, Palermo L, Pearson J, Cummings SR. Prevalent vertebral deformities predict hip fractures and new vertebral deformities but not wrist fractures. Study of Osteoporotic Fractures Research Group. J Bone Miner Res. 1999;14:821-8.

7. Ferrar L, Roux C, Feisenberg D, Gluer CC, Eastell R. Association between incident and baseline vertebral fractures in European women: vertebral fracture assessment in the Osteoporosis and Ultrasound Study (OPUS). Osteoporos Int. 2012;23:59-65.

8. Delmas PD, Genant HK, Crans GG, Stock JL, Wong M, Siris E, et al. Severity of prevalent vertebral fractures and the risk of sub- 
sequent vertebral and nonvertebral fractures: results from the MORE trial. Bone 2003; 33:522-32.

9. Melton III LJ, Atkinson EJ, Cooper C, O'Fallon WM, Riggs BL. Vertebral fractures predict subsequent fractures. Osteoporos Int. 1999;10:214-21.

10. Siris ES, Genant HK, Laster AJ, Chen P, Misurski DA, Krege JH. Enhanced prediction of fracture risk combining vertebral fracture status and BMD. Osteoporosis Int. 2007;18:761-70.

11. McCloskey EV, Vasireddy S, Threlkeld J, Eastaugh J, Parry A, Bonner $\mathrm{N}$, et al. Vertebral fracture assessment (VFA) with a densitometer predicts future fractures in elderly women unselected for osteoporosis. J Bone Miner Res. 2008;23:1561-8.

12. Compston J. Clinical and therapeutic aspects of osteoporosis. Eur J Radiol. 2009;71(3):388-91.

13. Boonen S, Kay R, Cooper C, Haentjens P, Vanderschueren D, Callewaert $F$, et al. Osteoporosis management: a perspective based on bisphosphonate data from randomized clinical trials and observational databases. Int J Clin Pract. 2009;63(12):1792-804.

14. Genant HK, Bouxsein ML, Pérez AD, Messina O ; Grupo de trabajo Bone Imagen Ósea del CSA de la Fundación Internacional de Osteoporosis. Iniciativa de Fractura Vertebral. Rev Metab Óseo y Min. 2011;9(3):94-7.

15. Genant $\mathrm{Hk}, \mathrm{Wu} \mathrm{CY}$, Kuijk CV, Nevitt MC. Vertebral fracture assessment using a semiquantitative technique. J Bone Min Res. 1993;8(9):1137-48.

16. Cockcroft DW, Gault MH. Prediction of creatinine clearance from serum creatinine. Nephron. 1976:16:31-41.

17. Cohen J. A coefficient of agreement for nominal scales. Educ Psych Meas. 1960;20:37-46.

18. Jager PL, Jonkman S, Koolhaas W, Stiekema A, Wolffenbuttel BHR, Slart RHJA. Combined vertebral fracture assessment and bone mineral density measurement: a new standard in the diagnosis of osteoporosis in academic populations. Osteoporos Int. 2011;22:1059-68.

19. Binkley N, Krueger D, Gangnon R, Genant HK, Drezner MK. Lateral vertebral assessment: a valuable technique to detect clinically significant vertebral fractures. Osteoporosis. 2005;16:1513-8.

20. Hospers IC, van der Laan JG, Zeebregts CJ, Nieboer P, Wolffenbuttel BH, Dierckx RA, et al. Vertebral fracture assessment in supine position: comparison by using conventional semiquantitative radiography and visual radiography. Radiology. 2009;251:822-8.

21. Schousboe JT, Debold Cr. Reliability and accuracy of vertebral fracture assessment with densitometry compared to radiography in clinical practice. Osteoporos Int. 2006;17:281-9.

22. Lindsay R, Silverman SL, Cooper C, Hanley DA, Barton I, Broy $\mathrm{SB}$, et al. Risk of new vertebral fracture in the year following a fracture. JAMA. 2001;285:320-3.
23. Vokes T, Bachman D, Baim S, Binkley N, Broy S, Ferrar L, et al. Vertebral fracture assessment: the 2005 ISCD Official Positions. J Clin Densitom. 2006;9:37-46.

24. Wu CY, Li J, Jergas M, Genant HK. Comparison of SO and quantitative techniques for the assessment of prevalent and incident vertebral fractures. Osteoporos Int. 1995;5:354-70.

25. Li J, Wu CY, Jergas M, Genant HK. Diagnosing prevalent vertebral fractures: a comparison between quantitative morphometry and a standardized visual (semiquantitative) approach. In: Genant HK, Jergas M, Van Kuijk C, editors. Vertebral fracture in osteoporosis. University of California, San Francisco. Radiology Research and Education Foundation. 1995; p. 271-9.

26. Grados F, Roux C, Vernejoul MC, Utard G, Sebert JL, Fardellone P. Comparison of four morphometric definitions and a semiquantitative consensus reading for assessing prevalent vertebral fractures. Osteoporos Int. 2001;12:716-22.

27. Delmas $P D$, van de Langerijt $L$, Watts NB, Eastell $R$, Genant $H$, Grauer A, et al.; IMPACT Study Group. Underdiagnosis of vertebral fractures is a worldwide problem: The IMPACT study. J Bone Miner Res. 2001;16(suppl 1):S139.

28. Genant HK, Mitlak BH, Myers S, Wang O. Radiographic fracture grade is related to clinical disease severity. Results from the rhPTH (1-34) fracture prevention study. Arthritis Rheum. 2000;43:S383.

29. Medicare Reimbursement Calculator. GE Healthcare 2006 Updated. Available at: http://www.gehealthcare.com/usen/community/ reimbursement/index.htlm. Accessed on: April 18, 2006.

30. Johansson $H$, Odén $A$, Lerner UH, Jutberger $H$, Loretzon $M$, Barrett-Connor $E$, et al. High serum adiponectin predicts incident fractures in elderly men: Osteoporotic Fractures in Men (MrOS) Sweden. J Bone Miner Res. 2012;6:1390-6.

31. Miller PD. Diagnosis and treatment of osteoporosis in chronic renal disease. Semin Nephrol. 2009;29:144-55.

32. Black DM, Schwartz AV, Ensrud KE, Cauley JA, Levis S, Quandt $S A$, et al. Effects of continuing or stopping alendronate after 5 years of treatment: the Fracture Intervention Trial Long-term Extension (FLEX): a randomized trial. JAMA. 2006;296:2927-38.

33. Quandt SA, Thompson DE, Schneider DL, Nevitt MC, Black DM. Effect of alendronate on vertebral fracture risk in women with bone mineral density $T$ scores of -1.6 to -2.5 at the femoral neck: the Fracture Intervention Trial. Mayo Clin Proc. 2005;80:343-9.

34. Wells GA, Cranney A, Peterson J, Boucher M, Shea B, Robinson $V$, et al. Etidronate for the primary and secondary prevention of osteoporotic fractures in postmenopausal women. Cochrane Database Sys Rev. 2008;CD003376.

35. Wells GA, Cranney A, Peterson J, Boucher M, Shea B, Robinson $\mathrm{V}$, et al. Alendronate for the primary and secondary prevention of osteoporotic fractures in postmenopausal women. Cochrane Database Syst Rev. 2008;CD001155. 